\title{
Publishing an Article: The Goal for a Graduate Course
}

\author{
Michael Hilke \\ McGill University
}

This essay discusses the effectiveness of a graduate course for physics students, with a course goal to write a publishable article on a modern research topic (graphene). I analyze the tools used to this end, which included Web 2.0 methods, in-class discussions and presentations, as well as extensive peer-review. In addition to producing a published article, this course led students to not only advance their mastery of a modern research topic but also to significantly improve their writing, discussion and presentation skills.

\section{Introduction}

I $\mathrm{n}$ most graduate schools, be it at the masters or doctorate levels, students are generally required to pass several graduate courses or seminars. The effectiveness of these courses is often questioned by both the students and their research advisors as a waste of time, since they can take precious resources away from engaging in research. While this is debateable, it is nonetheless important to examine what the main objective of a graduate course is. From a quick study of existing graduate course objectives, two themes emerge: 1) learning about current or recent research; and 2) improving skills in academic writing, presentations, and discussions. The question is: How can these two goals be achieved most effectively? The solution that I present below discusses the requirement to include a publication as the outcome of a graduate course.

\section{Course Description}

The following analysis is based on a single-semester physics graduate course that I taught in 2011 (Phys 634 at McGill) with an enrolment of 10 students. Most of the students were first-year masters students. The topic was chosen because of tremendous current interest in the research community as illustrated by approximately 6,000 articles published on graphene-related research in 2011 alone (Source: Web of Science). Graphene is a one-atom thick carbon sheet with exceptional optical, electronic, and mechanical properties. Research on graphene exploded in 2004 thanks to its discovery that year by Andre Geim and Konstantin Novoselov, who were subsequently awarded the Nobel Prize in Physics in 2010. If, as a professor, I find the amount of literature daunting, I can certainly understand the effect on a first-year graduate student. Nevertheless, I made the decision to offer a graduate course on this 'hot' topic with the goal of publishing a review article of the field, while restricting the focus on the experimental properties. The agreed upon title eventually became Experimental Review of Graphene (Cooper et al., 2012).

My argument is that such a goal of writing a review article for a graduate course addresses factors that lead to excellent learning outcomes in terms of: 1) learning about current or recent research; and 2) writing 
and presentation skills. In addition, it addresses the 'waste of time' argument in a powerful way, since it is easy for a graduate student to justify spending time on a course if it leads to a publication.

\section{Modern Science}

\section{Research}

Learning about current research is often done effectively starting at the undergraduate level, when students participate in research directly. This is justified, since involving undergraduate students in research is generally believed to lead to significant educational benefits (Gates, et al., 1999; Kardash, 2000; Seymour, Hunter, Laursen, \& Deantoni, 2004; Zydney, Bennett, Shahid, \& Bauer, 2002). Research at the undergraduate level can take several forms, including an original contribution in a laboratory environment or an extensive literature review with a synthesis of the main results, which can be seen as a significant research form on its own (Cooper, 1988). At the masters' level, the literature review is typically required for the thesis and often complemented by an original contribution. For a more conventional course setting, where a single instructor is in a classroom with many students, it is very difficult to conceive a course where original research like that performed in a laboratory environment can be achieved for a large student enrolment. By contrast, a research level literature review can easily be implemented in a single-instructor environment.

\section{Literature review}

Post-graduate students do not necessarily understand the concepts involved in writing a literature review, as they often underestimate the need for critique of the existing literature (Bitchener \& Banda, 2007). Thus, the starting point for our course Phys 634 was to have the students find all the existing reviews on the subject (in this case, graphene). As a by-product, this enabled an interesting discussion on various search tools and the use of up- and down-stream citations. While the students in class found more than 50 reviews, most of them were on a specific aspect of graphene (such as electronic properties of graphene), and it was realized quickly that there were none that were a comprehensive review of the experimental properties of graphene, which was the overextending topic of the course. In this context, a review is a scientific article that synthesizes existing published articles, which explains the large difference in number of articles (more than 6,000 ) compared to the number of reviews (less than $100)$ on the same topic.

\section{In-Class Discussions and Presentations}

The next step was to define a table of contents (TOC). The most valuable educational aspect was the active participation and in-class discussions induced by examining the possible topics to be included in the TOC. The key is to fairly quickly come-up with a TOC so that the substantive work can start, but at the same time it is important to value the input of each student, since they will spend a considerable amount of time with the topics included in the TOC. Once the TOC was defined, the content constituted the scientific material to be covered in the course. Each student was then made responsible for one section of the TOC. The first step for each student consisted of elaborating the content of the corresponding section and then defending it in-class by means of a presentation. It is similar to a research defence, where the presenter has to introduce the different subtopics in the literature review and defend their inclusion.

\section{Peer Review}

At this stage, the peer review process began. This happened first, through the critical discussions during the presentation, and later, through the peer review of each section by two randomly chosen students in class. While peer review has shown to be an effective method to improve writing skills (Berg, Admiraal, \& Pilot, 2006; Boud, Cohen, \& Sampson, 1999; Falchikov, 1995; Stefani, 1994; Topping, Smith, Swanson, \& Elliot, 2000), in our context, peer review was also used as a method by which to learn and understand the material. In a way, the reviewer plays the role of the student learning new material, while providing critical feedback, whereas the student receiving the review gets the critical feedback, which in turn, not only leads to improved writing but also to a better understanding of the subject matter (Lin, Liu, \& Yuan, 2001; Plutsky \& Wilson, 2004; Topping et al., 2000; Xiao \& Lucking, 2008).

\section{Web 2.0}

To increase the effectiveness of the peer review process, 
Web 2.0 was used extensively. Web 2.0 is the interactive form of the Internet. Because of its interactive nature, in particular between students and also between instructors and learners, Web 2.0 has gained considerable traction in online education (Beldarrain, 2006). Web 2.0 includes many different tools, including course web sites, blogs, broadcasts, and various forms of web-sharing tools such as wiki. Wikis are studied extensively for their effectiveness in teaching subject matters that involve collaborative efforts such as the one found in mutual peer-review and collective knowledge construction (Bold 2006; Xiao \& Lucking, 2008).

While most studies have focused on wiki designs, there are now many different tools available, which allow anyone to review and modify the content on a collection of documents on the web, both synchronously and asynchronously while enabling collaborative contentbuilding for all participants. We used Google-based web sharing software, including its web page creation tool as well as document sharing software ('Google Docs' now replaced by 'Google Drive'). With these tools, each participant can add to, comment on, and edit each document. Comments and changes were made directly on the shared document, where all changes could be traced by date and authorship, which also allowed for an effective evaluation tool for the instructor.

The peer review process worked along two lines: the commenting tool, which was very effective in terms of the initial peer review; and the editing tool, which was important for the later stages of composing the review article that involved the creation of a unified document. For example, each student used comments to provide feedback on the content and the writing style of a given section. In addition, one student was responsible for editing the tables of the entire document to make sure that they all followed the same formatting, while another student was responsible for the formatting of the figures, and yet another for organizing the references. Many of these tasks were made simpler by using a Latex based word editor, which is comprised of one text file containing all the written text, one reference file containing all the citations and another folder containing all the figures. The complete PDF output file (including all figures and citations) can be obtained using either a web- or home computer-based complier such as Latexlab or Miktex. Hence, Web 2.0 provides an interactive framework for peer and instructor assessment, and allows for collaborative content building, involving a large number of collaborators, where the feedback is immediate and multidimensional.

A large portion of the peer-review process was happening electronically outside of the classroom, while following a shared timetable with imposed deadlines. At the end, all sections of the document were peer- and instructor-reviewed between five and ten times while some sections required large amounts of rewrites, which were the responsibility of one of the in-class peer reviewers and not the student originally responsible for the corresponding section.

\section{Publishing}

The last phase involved getting the document into a publishable form. This was clearly an exciting moment for most of the students, since very few of them had published an article before. Moreover, the process contains many educational benefits. The first step was to decide which journal to publish in. Here, the quality, audience, and ethics of the various journals and publishers could be considered. An important deciding factor for the students in class was to use journals, which are either open access or belong to non-profit organizations. The document was further geared towards beginning researchers in the field, which also restricts the number of possible journals. The decision was made to first attempt a submission to a toptier journal, which could also lead to some high quality editorial feedback, before eventually submitting to a second-tier journal in the event that the reviews turned out to be too critical.

Another interesting educational moment related to the publishing process is the discussion on copyright and plagiarism as well as defining each individual's contribution. It was helpful that most publishers have clear guidelines that the students could familiarize themselves with. Moreover, the students obtained feedback from other researchers in the field (including referees and editors). These reviews had to be addressed in the resubmitted version.

While the first draft of the document was finished by the end of term, the entire journal review process took longer. However, all students (except one) agreed to continue meeting regularly after the end of term to finalize the document for publication, including making the necessary changes during the review process. This illustrates another potential difficulty with this exercise: 
How do we deal with unequal contributions? While during the term, variable contributions can be sanctioned by corresponding grades, the post-term contributions were purely voluntary and required a strong commitment from the students, which next to all had.

\section{Conclusion}

The produced document was subsequently accepted for publication in a second-tier peer reviewed open access scientific journal (Cooper et al., 2012) and co-authored by all students and also posted on an electronic archive server (ArXiv). The evaluation of the students was based on the quality of the writing and the presentation, the diligence in the review process, and the overall participation. The learning outcomes of the students was spectacular in terms of their confidence on the topic as assessed by the instructor based on the large number of discussions which occurred in class and online on various topics pertaining to the document. The students' self-confidence got a further boost from the acceptance letter of the journal. The course evaluations from the students were excellent.

\section{Acknowledgements}

The author would like to acknowledge the contributions of all the students in class Phys 634 (2011) for making this interesting exercise possible through their continued commitment.

\section{References}

Beldarrain, Y. (2006). Distance education trends: Integrating new technologies to foster student interaction and collaboration. Distance Education, 27, 139-153.

Berg, I.V.D., Admiraal, W., \& Pilot, A. (2006). Peer assessment in university teaching: Evaluating seven course designs. Assessment and Evaluation in Higher Education, 31(1), 19-36.

Bitchener, J. \& Banda, M. (2007). Postgraduate students' understanding of the functions of thesis sub-genres: the case of the literature review. New Zealand Studies in Applied Linguistics, 13(2), 89-102.
Bold, M. (2006). Use of wikis in graduate course work. Journal of Interactive Learning Research, 17(1), 5-14. Chesapeake, VA: AACE.

Boud, D., Cohen, R., \& Sampson, J. (1999). Peer learning and assessment. Assessment and Evaluation in Higher Education, 24(4), 413-426.

Cooper, D.R., D’Anjou, B., Ghattamaneni, N., Harack, B., Hilke, M., Horth, A., Majlis, N., Massicotte, M., Vandsburger, L., Whiteway, E., \& Yu, V. (2012). Experimental Review of Graphene, ISRN Condensed Matter Physics, 501686, 1-56.

Cooper, H. (1988). Organizing knowledge syntheses: A taxonomy of literature reviews. Knowledge in Society Spring, 104-126.

Falchikov, N. (1995). Peer feedback marking: Developing peer assessment. Innovations in Education and Training International, 32(2), 175-187.

Gates, A.Q., et al. (1999). Expanding participation in undergraduate research using the affinity group model. Journal of Engineering Education, 88(4), 409-414.

Kardash, C.M. (2000). Evaluation of an undergraduate research experience: Perceptions of undergraduate interns and their faculty mentors. Journal of Educational Psychology, 92, 191-201.

Lin, S.S.J., Liu, E.Z.F., \& Yuan, S.M. (2001). Webbased peer assessment: Feedback for students with various thinking-styles. Journal of Computer Assisted Learning, 17, 420-432.

Plutsky, S. \& Wilson, B. A. (2004). Comparison of the three methods for teaching and evaluating writing: A quasi-experimental study. The Delta Pi Epsilon Journal, 46(1), 50-61.

Seymour, E., Hunter, A.B., Laursen, S.L., \& Deantoni, T. (2004). Establishing the benefits of research experiences for undergraduates in the sciences: First findings from a three-year study. Science Education, 88(4), 493-534. 
Stefani, L.A.J. (1994). Peer, self and tutor assessment: Relative reliabilities. Studies in Higher Education, 19(1), 69-75.

Topping, K., Smith, F.F., Swanson, I., \& Elliot, A. (2000). Formative peer assessment of academic writing between postgraduate students. Assessment and Evaluation in Higher Education, 25(2), 149-169.

Xiao, Y. \& R. Lucking, R. (2008). The impact of two types of peer assessment on students' performance and satisfaction within a Wiki environment. The Internet and Higher Education, 11, 186-193.

Zydney, A.L., Bennett, J.S., Shahid, A., \& Bauer, K.W. (2002). Impact of undergraduate research experience in engineering. Journal of Engineering Education, 91(2), 151-157.

\section{Biography}

Michael Hilke is Associate Professor of Physics at McGill University. He is the head of the Quantum Nano Electronics Laboratory, and involves many undergraduate and graduate students in his research on advanced materials and quantum engineering. 